\title{
Root and shoot glucosinolates: a comparison of their diversity, function and interactions in natural and managed ecosystems
}

\author{
Nicole M. van Dam • Tom O. G. Tytgat • \\ John A. Kirkegaard
}

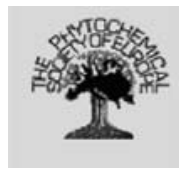

Received: 1 February 2008/Accepted: 29 April 2008/Published online: 6 June 2008

(C) The Author(s) 2008

\begin{abstract}
The role of glucosinolates in aboveground plant-insect and plant-pathogen interactions has been studied widely in both natural and managed ecosystems. Fewer studies have considered interactions between root glucosinolates and soil organisms. Similarly, data comparing local and systemic changes in glucosinolate levels after root- and shoot-induction are scarce. An analysis of 74 studies on constitutive root and shoot glucosinolates of 29 plant species showed that overall, roots have higher concentrations and a greater diversity of glucosinolates than shoots. Roots have significantly higher levels of the aromatic 2-phenylethyl glucosinolate, possibly related to the greater effectiveness and toxicity of its hydrolysis products in soil. In shoots, the most dominant indole
\end{abstract}

Electronic supplementary material The online version of this article (doi:10.1007/s11101-008-9101-9) contains supplementary material, which is available to authorized users.

N. M. van Dam $(\bowtie) \cdot$ T. O. G. Tytgat

Netherlands Institute of Ecology (NIOO-KNAW),

PO Box 40, 6666 ZG Heteren, The Netherlands

e-mail: n.vandam@nioo.knaw.nl

T. O. G. Tytgat

Laboratory of Nematology, Wageningen University and Research Centre, PO Box 8123, 6700 ES Wageningen, The Netherlands

J. A. Kirkegaard

CSIRO, Plant Industry, GPO Box 1600, 2610 Canberra,

ACT, Australia glucosinolate is indol-3-ylglucosinolate, whereas roots are dominated by its methoxyderivatives. Indole glucosinolates were the most responsive after jasmonate or salicylate induction, but increases after jasmonate induction were most pronounced in the shoot. In general, root glucosinolate levels did not change as strongly as shoot levels. We postulate that roots may rely more on high constitutive levels of glucosinolates, due to the higher and constant pathogen pressure in soil communities. The differences in root and shoot glucosinolate patterns are further discussed in relation to the molecular regulation of glucosinolate biosynthesis, the within-tissue distribution of glucosinolates in the roots, and the use of glucosinolate-containing crops for biofumigation. Comparative studies of tissue-specific biosynthesis and regulation in relation to the biological interactions in aboveground and belowground environments are needed to advance investigations of the evolution and further utilization of glucosinolates in natural and managed ecosystems.

Keywords Allelopathy · Induced responses · Isothiocyanates · Plant-environment interaction . Soil ecology
Abbreviations
GSL Glucosinolates
ITC Isothiocyanates 


\section{Introduction}

Glucosinolates (GSL) are a widely studied class of plant chemical compounds with a large structural diversity. Over $120 \mathrm{GSL}$ have been identified to date, mainly in species belonging to the Brassicaceae (Fahey et al. 2001). The large diversity in GSL profiles between and within species has been extensively recorded, especially for various crop cultivars and varieties, and the model plant species Arabidopsis thaliana. However, there has been a strong focus on GSL analyses of aboveground plant organs, probably because the main crucifer crops, such as oil seed rape (Brassica napus), cabbages and broccoli (B. oleracae), have their harvestable parts aboveground. In these crops GSL influence important quality and flavour characteristics of the produce, as well as resistance against non-adapted pathogen and insect pests (Chew 1988; Mithen 2001). Similarly, studies on the induction of GSL mainly focus on the effects of aboveground herbivores or pathogens. Consequently, constitutive and induced GSL levels and profiles in roots are under-explored relative to those of aboveground plant parts (van Dam et al. 2003).

Evolutionary theory predicts that the large diversity of plant defence compounds, such as GSL, reflects the present and past selection pressures experienced by plants in their natural environment (Jones and Firn 1991). Consequently, it has been hypothesized that the vast variety of GSL found in plant species has arisen from an evolutionary arms race with their enemies (Benderoth et al. 2006). Assuming that GSL serve a defensive function in roots as well, we may expect similar natural selection processes to act on belowground GSL composition. However, the kind of selection pressures exerted by soil processes may differ completely from the aboveground processes. First, the physical and chemical environment of roots is completely different than that of aerial parts. This may require different compounds in roots and shoots to serve similar biological functions. Second, the aboveground and belowground communities interacting with the plant differ as well. On the one hand, pressures exerted by soil biota may be more constant, because most agricultural and natural soils are truly 'living soils' full of micro-organisms and nematodes 'waiting' for a plant root to feed on (Coleman et al. 2004). On the other hand, the composition of the soil community interacting with an individual plant may be much more random. Heterotrophic soil organisms are often concentrated in nutrient-rich patches in the soil (Coleman et al. 2004). Moreover, soil biota such as micro-organisms and nematodes are far less mobile than aboveground herbivores and pathogens, which can be transported over longer distances by wind and rain (van der Putten et al. 2001). Consequently, the distribution of soil biota is heterogeneous, so predicting which soil organisms a root will encounter when the seed starts to germinate is difficult. Reasoning along the same evolutionary lines, the induction of root and shoot GSL may differ as well. If roots have a higher risk of exposure to herbivores, it may be beneficial to constitutively produce high levels of GSL (Karban et al. 1999). Although these assumptions are rooted in ecological-evolutionary theory, the same processes may apply to breeding for crop resistance. Artificial selection procedures have successfully been aiming at contrasting selection trajectories for GSL levels in different organs. For example, breeders have been selecting for both lower GSL levels in seeds to improve oil quality for consumption, as well as for higher GSL levels in roots to increase resistance against phytophagous nematodes (Potter et al. 2000), or suppress fungal diseases in following cereals species (Kirkegaard et al. 2001).

Here we comprehensively summarize studies that have analyzed both root and shoot GSL levels in the same plant, and identify differences between the two. Similarly, we summarize data on aboveground and belowground GSL induction. To facilitate the straightforward comparison of induced GSL responses, we focus on those studies using induction hormones instead of a variety of herbivores and pathogens. In addition to local induction processes, we also discuss aboveground belowground interactions between induced responses. Interactions between root- and shoot-induced responses have received increasing interest lately, because they may interfere with local induction of optimal defence responses and significantly affect higher trophic levels associated with plants (Soler et al. 2005; van Dam and Raaijmakers 2006). The differences in root and shoot GSL levels and profiles will be linked to their known functions in pathogen and insect resistance, as well as discussed in the light of the different 
physical properties of air and soil. In addition, we discuss how the existing knowledge on the molecular regulation of GSL biosynthesis (reviewed by Gigolashvili et al., this issue; Kliebenstein, this issue) and the within tissue distribution of root GSL will help to understand the observed patterns. Finally, we consider the application of GSL-containing crops for biofumigation in agricultural systems, and identify directions for future research that will help us to increase our understanding of the roles of GSL in natural and managed ecosystems.

\section{Constitutive levels of root and shoot GSL}

A comprehensive literature search yielded records of root and shoot GSL levels and profiles of 29 plant (sub)species (Table 1). Not surprisingly, the majority of the records were on members of the Brassicaceae (69 out of 74), mostly cultivated Brassica species and varieties (41 of 69). In addition, we also found several records of wild plant species belonging to other families such as the Caricaceae, Moringaceae, Salvadoraceae and Tropaeolaceae (Table 1). Despite a large variation in how the plants were grown, the ontogenetic stage of the plants, the season in which they were harvested, and the detail to which the analyses were performed at the tissue level, we were able to identify several general trends in the dataset. Overall, roots had higher total GSL concentrations than shoots (Appendix 1 root/shoot ratio average, Wilcoxon's matched pairs test, $n=47, Z=4.98$, $P<0.001)$. Root tissues on average had $4.5( \pm 5.6$ $\mathrm{SD})$ times more GSL than shoot tissues. Only 15 records reported root levels that were lower than shoot levels (Appendix 1). Three of these records were on flowering B. nigra (Kirkegaard and Sarwar 1998; van Dam et al. 2004; Bellostas et al. 2007). In this species, the general rule of a high root/shoot GSL ratio only applies to the vegetative stage; roots of vegetative plants with four leaves had 3.7 times higher GSL levels than their shoots (Bellostas et al. 2007). In broccoli and Arabidopsis thaliana plants, on the other hand, it was the sprouts and young rosettes that had a lower root/shoot GSL ratio than later stages of the same species (Appendix 1). Our analysis also showed that roots on average have a greater diversity of GSL than shoots (Table 2). We cannot rule out the possibility that this is due to the higher overall GSL levels in roots, and thus more compounds exceed the HPLC detection limit in root extracts.

In addition to the differences in total GSL levels, we also found significant differences in GSL composition between roots and shoots. Even though the fractions of indole GSL were similar in roots and shoots, there was a distinct difference in the composition of this group. In shoots, the predominant indole GSL is indol-3-ylmethylglucosinolate (I3M; 60\%, Table 2), whereas in the roots the 1- and 4-methoxy derivatives dominate (only $23 \%$ is I3M). In 30 of the 56 records detailing root GSL profiles, 1-methoxyindol-3-ylmethylglucosinolate (1MI3M) was the most prominent indole GSL in the roots and in 14 cases 4-methoxyindol-3-ylmethylglucosinolate (4MI3M; Appendix 1). Recently it was shown that $1 \mathrm{MI} 3 \mathrm{M}$ and $4 \mathrm{MI} 3 \mathrm{M}$ and their breakdown products are more potent deterrents of generalist aphid feeding than their precursor I3M (Kim and Jander 2007; Agerbirk et al., this issue). I3M breakdown products, on the other hand, were found to be more effective inhibitors of Leptospaeria maculans, a fungus causing stem canker in rapeseed cultures, than those of $1 \mathrm{MI} 3 \mathrm{M}$ (Mithen and Lewis 1986). Unfortunately, this class of GSL has so far been little studied for its involvement in resistance against herbivores and pathogens, which makes it difficult to speculate how specific aboveground and belowground processes may have contributed to the observed difference. The lack of attention for indole GSL is probably due to the longstanding assumption that they are less toxic or deterrent than aliphatic GSL. The reason is that they do not yield stable isothiocyanates (ITC) upon contact with myrosinase, but produce the less toxic nitriles and ascorbigens, depending on the presence of modulating proteins such as epithiospecifier protein (ESP) and epithiospecifier modifier 1 protein (ESM1; Agerbirk et al. 1998; Burow et al. 2008).

Another significant difference between root and shoot GSL profiles was the levels of 2-phenylethylglucosinolate (2PE-GSL). Especially in Brassica species, 2PE-GSL is often the major GSL in the root profile, whereas it is either absent or found in trace amounts in shoots (Table 2). In the argument for an evolutionary basis for the predominance of 2PE-GSL in roots, it is revealing to consider the comparative advantage of that compound over GSL with other side-chain structures. Firstly, its break-down product 
Table 1 Plant species, the number of records (natural or cultivated) per species that were included in our analysis of root and shoot GSL, and the sources for the data

\begin{tabular}{|c|c|c|c|}
\hline Plant species & $\begin{array}{l}\text { Records on } \\
\text { natural species }\end{array}$ & $\begin{array}{l}\text { Records on } \\
\text { cultivated species }\end{array}$ & Source references \\
\hline $\begin{array}{l}\text { Alliaria petiolata M. Bieb.) Cavara } \\
\quad \text { \& Grande }\end{array}$ & 2 & & Vaughn and Berhow (1999) \\
\hline Arabidopsis thaliana (L.) Heynh. & 5 & & Petersen et al. (2002) and Brown et al. (2003) \\
\hline $\begin{array}{l}\text { Armoracia rusticana P. Gaertn., } \\
\text { B.Mey \& Scherb. }\end{array}$ & 1 & & Li and Kushad (2004) \\
\hline Azima tetracantha $\mathrm{L}$. & 1 & & Bennett et al. (2004) \\
\hline Barbarea vulgaris $\mathrm{R} . \mathrm{Br}$. & 2 & & $\begin{array}{l}\text { van Leur et al. (2006), van Leur (2008) and van } \\
\text { Leur et al. (2008) }\end{array}$ \\
\hline Brassica campestris L. & & 1 & Kirkegaard and Sarwar (1998) \\
\hline Brassica carinata A. Braun. & & 3 & $\begin{array}{l}\text { Kirkegaard and Sarwar (1998) and Bellostas et al. } \\
\text { (2007) }\end{array}$ \\
\hline Brassica fruticulosa Cirillo & & 1 & Kirkegaard and Sarwar (1998) \\
\hline Brassica juncea (L.) Czern. & & 7 & $\begin{array}{l}\text { Kirkegaard and Sarwar }(1998,1999) \text { and Bellostas } \\
\text { et al. (2007) }\end{array}$ \\
\hline Brassica napus L. & & 10 & $\begin{array}{l}\text { Birch et al. (1992) and Kirkegaard and Sarwar } \\
(1998,1999)\end{array}$ \\
\hline Brassica nigra (L.) W.D.J. Koch & 3 & 1 & $\begin{array}{l}\text { Kirkegaard and Sarwar (1998), van Dam et al. } \\
\text { (2004) and Bellostas et al. (2007) }\end{array}$ \\
\hline Brassica oleracea L. & 3 & 13 & $\begin{array}{l}\text { Birch et al. (1992), Rosa (1997), Rosa and } \\
\text { Rodrigues (1998), Castro et al. (2004), Charron } \\
\text { and Sams (2004), Aires et al. (2006) and Gols and } \\
\text { Van Dam (unpublished data) }\end{array}$ \\
\hline Brassica rapa $\mathrm{L}$. & & 3 & Bellostas et al. (2007) and Smetanska et al. (2007) \\
\hline Brassica rapa $\mathrm{L}$. subsp oleifera DC. & & 2 & Loivamäki et al. (2004) \\
\hline Cardamine cordifolia A. Gray & 1 & & Rodman and Louda (1984) \\
\hline $\begin{array}{l}\text { Cardamine (Dentaria) diphylla } \\
\text { (Michx.)Wood. }\end{array}$ & 1 & & Feeny and Rosenberry (1982) \\
\hline $\begin{array}{l}\text { Cardamine (Dentaria) maxima } \\
\text { (Nutt.)Wood. }\end{array}$ & 1 & & Feeny and Rosenberry (1982) \\
\hline Carica papaya $\mathrm{L}$. & & 1 & Ludwig-Müller et al. (1999) \\
\hline Diplotaxis tenuifolia (L.) DC. & & 1 & Kirkegaard and Sarwar (1998) \\
\hline Eruca sativa Mill. & 1 & 1 & $\begin{array}{l}\text { Kirkegaard and Sarwar (1998) and Kim and Ishii } \\
\text { (2006) }\end{array}$ \\
\hline Moringa oleifera Lam. & 1 & & Bennett et al. (2003) \\
\hline $\begin{array}{l}\text { Moringa stenopetala (Baker f.) } \\
\text { Cufodontii }\end{array}$ & 1 & & Bennett et al. (2003) \\
\hline Sinapis alba $\mathrm{L}$. & & 1 & Kirkegaard and Sarwar (1998) \\
\hline Sinapis arvensis $\mathrm{L}$. & & 1 & Kirkegaard and Sarwar (1998) \\
\hline Sisymbrium orientale $\mathrm{L}$. & & 1 & Kirkegaard and Sarwar (1998) \\
\hline Thlaspi arvense L. & 1 & & Tolrà et al. (2006) \\
\hline Thlaspi caerulens J \& C. Presl. & 1 & & Tolrà et al. (2001) \\
\hline Thlaspi praecox Wulfen & 1 & & Tolrà et al. (2006) \\
\hline Tropaeolum majus L. & 1 & & Ludwig-Müller et al. (1999) \\
\hline Grand total & 27 & 47 & \\
\hline
\end{tabular}

Original data are provided in the electronic appendix 
Table 2 Average number of glucosinolates and the contribution of specific glucosinolates to root and shoot profiles

\begin{tabular}{|c|c|c|c|c|c|c|c|c|c|c|}
\hline \multirow[t]{2}{*}{ Parameter scored } & \multicolumn{3}{|c|}{ Shoot } & \multicolumn{3}{|c|}{ Root } & \multicolumn{4}{|c|}{ Statistical analysis } \\
\hline & $n$ & Mean & Std. dev. & $n$ & Mean & Std. dev. & Test & Pairs & $Z$-value & $P$ \\
\hline Number of GSL & 63 & 5.54 & 2.83 & 70 & 6.89 & 3.36 & Sign test & 51 & 3.08 & 0.002 \\
\hline Fraction indole GSL/total GSL & 69 & 0.21 & 0.22 & 70 & 0.17 & 0.19 & Wilcoxon & 69 & 1.38 & 0.17 \\
\hline Fraction I3M/indole GSL & 57 & 0.60 & 0.35 & 63 & 0.23 & 0.23 & Wilcoxon & 57 & 5.43 & $<0.001$ \\
\hline Fraction 2PE/total GSL & 61 & 0.06 & 0.14 & 61 & 0.41 & 0.30 & Wilcoxon & 61 & 6.11 & $<0.001$ \\
\hline
\end{tabular}

The contribution of the specific glucosinolates was calculated as a fraction by dividing the concentration of the specific glucosinolate over the total glucosinolate concentration of the same tissue. Abbreviations: $n=$ number of records in which this parameter was quantified; GSL = glucosinolate; I3M = indol-3-ylmethylGSL; 2PE = 2-phenylethyl GSL. Pairs = non-ties/full pairs included in analysis

2-phenylethyl isothiocyanate (2PE-ITC) is among the least volatile (Sarwar et al. 1998), whereas volatile losses are one of the major causes for ITC loss from soil (Brown and Morra 1997). Secondly, 2PE-GSL break-down products are among the most hydrophobic and as a consequence less prone to leaching losses from the soil (Laegdsmand et al. 2007). Thirdly, the aromatic GSL are more lipophilic, which increases membrane permeability, thus contributing to the higher contact toxicity often reported for the aromatic ITCs. Moreover, the ethyl bridge linking the phenyl group with the functional ITC may act to hold the active ITC free of the soil organic matrix allowing better contact with soil organisms (Potter et al. 1998), a structural feature absent from benzyl ITC which is less prevalent in roots (Borek et al. 1998). Even though a recent lab study showed that the volatile insecticidal activity of 2PE-ITC may be mitigated by the soil environment more than that of other ITCs (Matthiessen and Shackleton 2005), many other studies showed that 2-PE ITC was among the most toxic upon direct contact to a range of soil-borne organisms, including soil insects (Borek et al. 1995, 1998), pathogenic fungi (Sarwar et al. 1998), phytophagous root nematodes (Potter et al. 1999, 2000) and wheat seeds (Bialy et al. 1990). 2PE-GSL is also thought to be one of the compounds preventing the association of Brassicaceous plants with arbuscular mycorrhizal fungi (AM). Both agriculturally important as well as wild Brassica species are known to be non-mycorrhizal (Harley and Harley 1987). 2-PE GSL was only present in the roots of non-AM hosts, and was absent in the AM host species, such as the non-Brassica species Tropaelum majus and Carica papaya. The roots of these species contained other
GSL including the closely related aromatic benzylGSL (Vierheilig et al. 2000). Since no plants known to contain 2PE-GSL have been shown to host AM to date, the possibility remains that it may be a potent inhibitor of AM infection. However, the fact that other non-Brassica species such as white lupins (Lupinus alba) are also non-hosts indicates that mechanisms unrelated to GSL are involved as well.

Experiments with artificially selected canola varieties have shown that it is possible to selectively breed for higher 2PE-GSL levels without affecting shoot or seed GSL levels (Potter et al. 2000; Kirkegaard et al. 2001). These artificial selection experiments suggest that natural selection processes may have contributed to independent selection for GSL levels and profiles in roots and shoots in a similar fashion.

\section{Shoot and root induction of GSL}

Even though GSL are present constitutively in all plant tissues (Wittstock and Gershenzon 2002), very often they increase upon herbivore damage, pathogen infection or application of plant hormones. Most of the studies published on the induction of GSL focus on aboveground induction processes. However, several recent studies have shown that root induction may cause both local and systemic changes in GSL levels as well. Root fly feeding, for example, systemically increases 2-propyl GSL levels in the leaves and indole GSL levels in the roots of Brassica nigra (Soler et al. 2005; van Dam and Raaijmakers 2006).

Straightforward comparisons between induced responses occurring in roots and shoots are difficult, 
because most phytophagous organisms feed specifically on only one of the organs. One way to circumvent this problem is to use induction hormones such as jasmonic acid (JA, or its methylated form MeJA), or salicylic acid (SA/MeSA). These naturally occurring phytohormones can be applied quantitatively to either roots or shoots. When analyzing studies using these hormones to induce cruciferous species, consistent patterns emerge, despite considerable differences in the time-frame of the experiment, and the amount or form in which the induction hormones were applied (Table 3). Jasmonates, for example, are potent inducers of shoot indole GSL. In 17 out of the 20 experiments the shoot indole GSL levels increased significantly after application of jasmonates. This increase was both rapid and long-lasting: in several experiments the indole GSL levels doubled within 1 day after treatment and they stayed 10-20 times higher than in control plants for 14-30 days after induction (Table 3). This considerable increase was jasmonate-specific, since salicylate application generally elicited lower or no increases of indole GSL (Table 3).

Interestingly, in two of the three cases reporting no changes in indole GSL levels, the JA was applied to the roots. Similarly, we found that only shoot JA application consistently increased indole GSL in three ecotypes of Arabidopsis thaliana, whereas the same amount of JA added to the roots did not (Fig. 1). The increase of indole GSL biosynthesis after shoot application of jasmonates appears to be very specific, because it was occurring even when there was no significant increase of total GSL levels (KON in Fig. 1). Root JA application, on the other hand, may specifically increase aliphatic GSL levels in the shoot as was observed in a feral B. oleracea (Table 3; van Dam et al. 2004). Aliphatic and indole GSL are derived from different pathways that are regulated by specific transcription factors belonging to the Myb family (Gigolashvili et al. 2007a; Hirai et al. 2007). It is as yet unknown which physiological mechanism underlies the organ specific differential induction of these two biosynthetic pathways by root or shoot applied JA. Possibly, JA is conjugated with a different amino acid in roots and shoots, resulting in different signalling cascades and GSL responses (Staswick and Tiryaki 2004).

The aliphatic and aromatic GSL in the shoot did not increase substantially after jasmonate application
(Table 3). Both the fold-changes as well as the frequencies with which an increase was reported were less than for the indole GSL. Salicylate application did not increase the levels of these compounds either, which may indicate that these GSL are generally less responsive to the application of induction hormones and possibly other induction events.

As for the constitutive GSL levels, there are fewer reports on root GSL responses than on shoot responses. Although several studies report GSL responses in the roots after JA or SA treatment, roots do not respond as strongly as the shoots within the same plant (Table 3). Root indole GSL, for example, increased in less than half of the experiments quantifying root GSL, even if the JA was applied to the root itself (Table 3). This indicates that the induction of similar root and shoot GSL biosynthetic pathways is differentially regulated, for example by root and shoot specific Myb factors (Czechowski et al. 2004). The relatively low response of the roots after induction, together with the higher constitutive levels in this organ, suggests that roots may have a different optimal defence strategy. As suggested by Karban et al (1999) this may be related to the higher chances of herbivore and pathogen attack belowground.

Because GSL are biosynthetically related, the induced changes in GSL are not independent. Multivariate analyses, such as Principal Component Analysis and Partial Least Squares Regression may reveal correlations between different GSL within changing GSL profiles after induction treatments (J.J. Jansen and N.M. van Dam, unpublished results). Together with gene expression analysis, they may reveal the regulatory network underlying specific GSL responses after root and shoot induction.

\section{Molecular regulation of GSL biosynthesis}

The most plausible physiological explanation for the observed differences in root and shoot patterns is that both organs have a different regulation of GSL biosynthesis and turn-over. Transportation of GSL via the phloem over long distances (Chen et al. 2001) is not likely to be the main cause. This is supported by the observation that induction of specific indole GSL by aphids occurs in detached leaves as well, precluding a role for transport from the roots (Kim and Jander 2007). Moreover, GSL metabolism is 


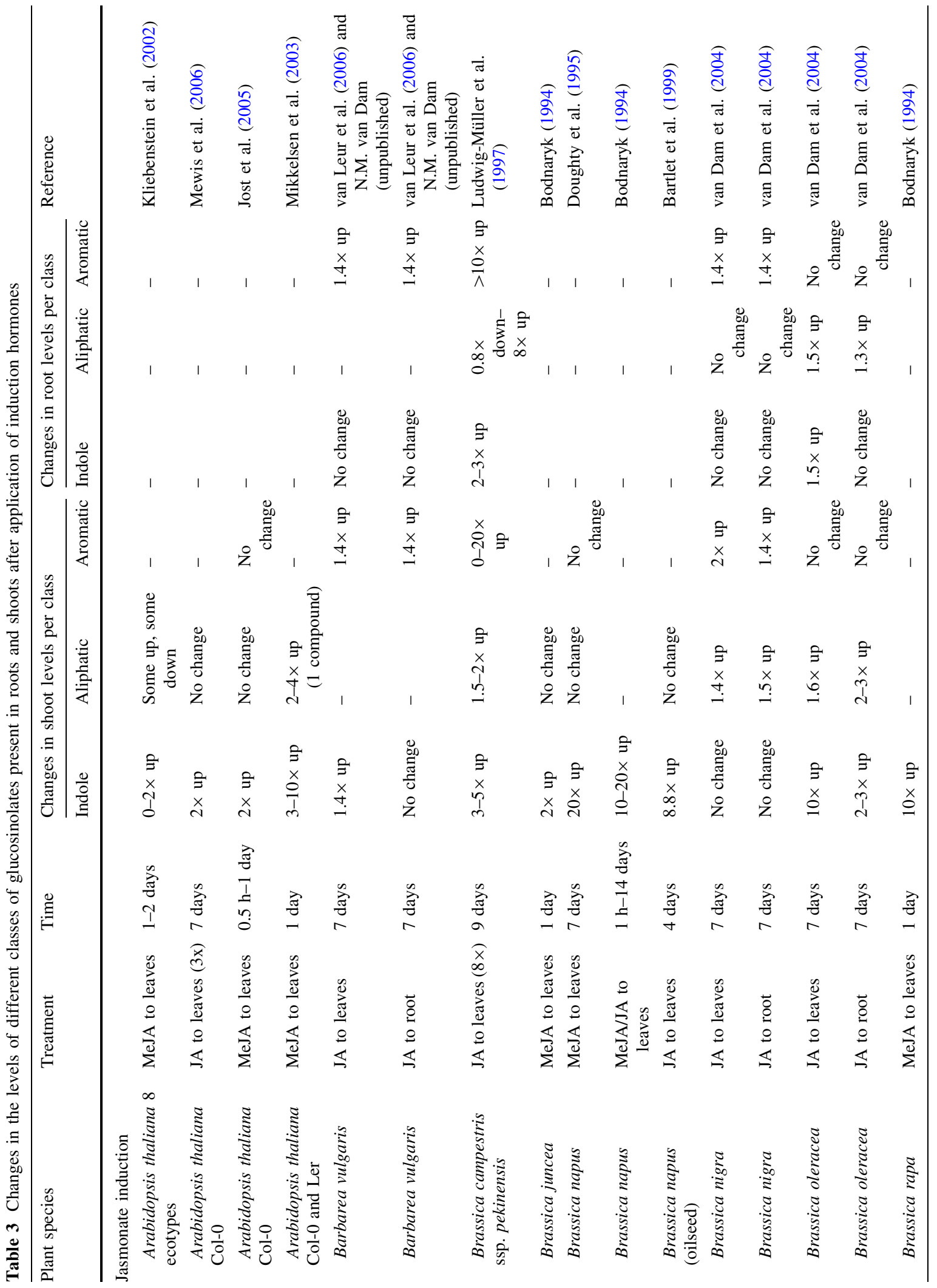




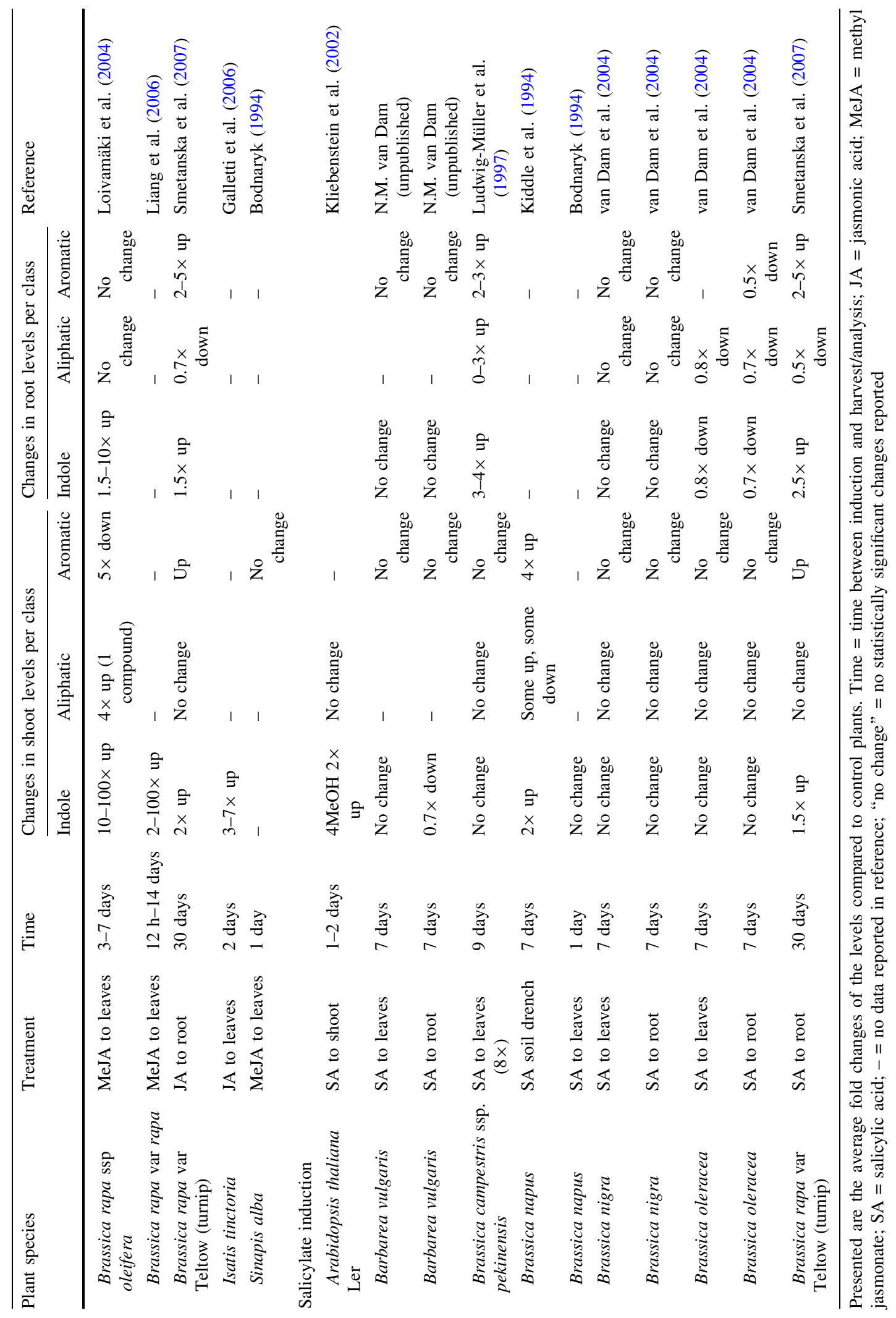




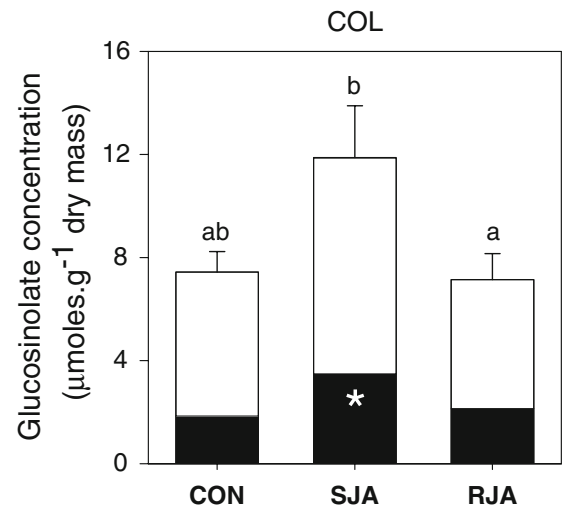

Fig. 1 Indole, aliphatic and total GSL levels (bars are SEM of total levels) of Arabidopsis thaliana shoots 7 days after induction with $50 \mu \mathrm{g}$ jasmonic acid to the shoots (SJA) or to the roots (RJA). Control (CON) plants were treated with equal amounts of acidic water. COL $=$ Columbia ecotype $(n=10$ per treatment), Ler $=$ Landsberg erecta $(n=6)$,

highly integrated with plant growth. For example, there is a tight direct link between indole GSL biosynthesis and the principal auxin, indol-3-acetic acid (IAA) metabolism; they are both derived from tryptophan and they share the first dedicated step in their biosynthesis (reviewed in Grubb and Abel 2006). IAA is a key regulator in plant development and tissue differentiation processes (De Smet and Jürgens 2007). Consequently, many GSL mutants and over-expressing transformants show severe morphological phenotypes, such as increased root branching or stunted shoot growth (Skirycz et al. 2006; Gigolashvili et al. 2007a). In turn, this also implies that environmental factors, both biotic and abiotic, affecting IAA-regulated changes in growth rate or shoot/ root ratios, may affect the levels of indole GSL. Additionally, GSL biosynthesis may also be interfering with defence signalling pathways. Increased accumulation of aromatic GSL was shown to stimulate SA-mediated defenses, while suppressing JA-dependent defenses (Brader et al. 2006). Hence the question of what makes the GSL profile different between roots and shoots may be intimately associated with the physiological differences between root and shoot metabolism in general.

Recently, much progress has been made in identifying transcription factors of GSL biosynthesis (Yan and Chen 2007; Gigolashvili et al., this issue). Several of these GSL transcription factors showed organ
LER

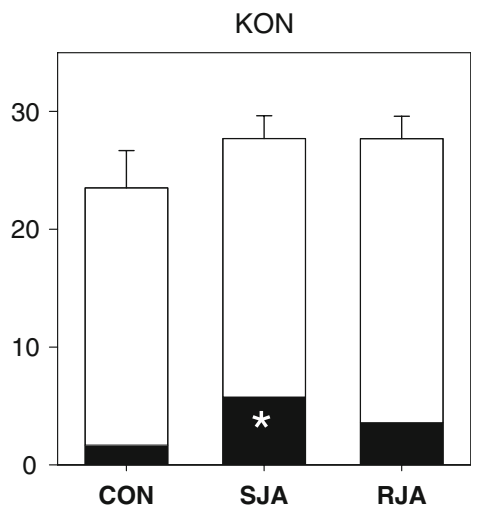

$\mathrm{KON}=$ Kondara $(n=6)$. Different letters over bars indicate significant difference in total GSL levels (Tukey HSD post-hoc analysis after ANOVA). The stars in the indole GSL bars indicate significant differences in indole GSL levels between the SJA treatment and the other two treatments

specific expression patterns (Gigolashvili et al. 2007a, b, 2008). However, a more detailed analysis of the tissue specific regulation of GSL synthesis and turn-over, as well as integration into the general metabolism is needed to elucidate the extent to which differential expression of these genes is responsible for the differences that emerged from our meta-analysis.

\section{Tissue-specific distribution of the GSL-myrosinase system in roots}

The tissue-specific distribution of the GSL-myrosinase system can provide some clues as to its likely mode of action, but again there is a dearth of information for roots of field-grown plants. In aboveground tissues, the defensive mode of action against generalist herbivores, particularly during seedling recruitment, is associated with a concentration of GSL in young, growing tissues and reproductive organs (Petersen et al. 2002; Brown et al. 2003; Lambdon and Hassall 2005). Whether the within root distribution of GSL follows similar rules is an open issue. A quick survey of the few data available shows that among five Brassica species, there may be consistent allocation patterns within roots as well (Table 4). When ranked within species, primary and lateral roots had the highest levels of GSL and a larger fraction of 2PE-GSL (Table 4; Kruskall-Wallis analysis on ranks, total GSL: $P=0.0186,2$ PE-GSL 
Table 4 Average within root glucosinolate levels $\left(\mu \mathrm{mol} \mathrm{g}{ }^{-1}\right.$ dry mass; standard deviation between brackets) of 5 Brassica species: B. juncea (2 varieties) and B. napus (2 varieties; Kirkegaard and Sarwar 1999), B. rapa (Smetanska et al. 2007),

\begin{tabular}{lccccccc}
\hline Root type & $n$ & Aliphatic GSL & Aromatic GSL & Indole GSL & Total GSL & 2PE/total & Indole/total \\
\hline Fine/secondary & 8 & $2.9(3.3)$ & $3.7(3.3)$ & $3.6(2.3)$ & $10.2(7.6)$ & $0.31(0.14)$ & $0.37(0.22)$ \\
Lateral & 4 & $8.1(11.0)$ & $17.3(13.5)$ & $2.5(1.5)$ & $27.9(25.0)$ & $0.62(0.12)$ & $0.12(0.11)$ \\
Tap/primary & 8 & $10.0(12.5)$ & $9.5(9.2)$ & $1.4(1.2)$ & $20.9(22.1)$ & $0.43(0.20)$ & $0.10(0.12)$ \\
\hline
\end{tabular}

2PE = 2-phenylethyl GSL; GSL = glucosinolates

fraction $P=0.018$ ). The fine roots, on the other hand, showed a significantly larger proportion of indole GSL (Table 4, Kruskall-Wallis on ranks, $P=0.0034$ ), which may be due to the fact that actively growing root tips produce high levels of the biosynthetically closely related IAA (Grieneisen et al. 2007).

We know of only one recent study where GSL have been investigated in separated portions of individual roots and quantified in individual cells (McCully et al. 2008). In this study, intact canola roots were cryo-fixed and the vacuoles of individual cells were targeted for elemental sulphur analysis using X-ray microanalysis $(E D X)$ while the specimens were observed under a

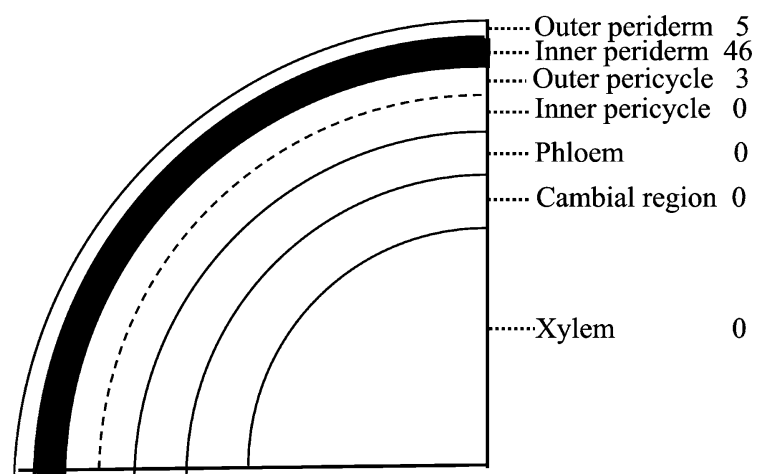

Fig. 2 Schematic of a cross section of a field-grown canola root at early flower development. Numbers indicate glusocinolate concentrations $(\mathrm{mM})$ in individual cells of secondary tissues (including proliferated pericycle), determined by quantitative, cell-specific cryo-analytical analysis of [S] (see McCully et al. 2008). The numbers are mean values for all cells analysed in each tissue region. GSL concentrations of individual cells ranged fairly widely in the three outer tissues, but many more cells with high concentrations were consistently found in the inner periderm (up to $200 \mathrm{mM}$; shown as dark band). The mean GSL concentration of the top $25 \%$ of inner periderm cells analysed was $103 \mathrm{mM}(n=96)$, and $32 \mathrm{mM}(n=71), 34 \mathrm{mM}(n=65)$, and $10 \mathrm{mM}(n=168)$ for cells of the outer periderm, and outer and inner pericycle, respectively. Cells of the phloem, cambial region and xylem $(n=80,35,42$, respectively) had no quantifiable glucosinolates
B. nigra (flowering and rosettes; van Dam and Raaijmakers 2006; Soler et al. 2007), feral B. oleracea (van Dam and Raaijmakers 2006)

cryo-scanning electron microscope (SEM). The quantitative cryo-analytical analysis with a SEM showed that the highest concentrations of GSL were found in two cell layers just under the outermost layer of roots with secondary growth. Up to $100 \times$ the published GSL concentrations for whole roots were determined for individual cells in these peripheral layers (Fig. 2). Cells of primary tissues had negligible GSL levels. Myrosinase idioblasts, on the other hand, were confined to secondary phloem and inner pericycle. The authors conclude that gross mechanical damage to the mature roots would allow ITC release, whereas less invasive damage may not. GSL, however, would be released continuously to the rhizosphere as roots expand circumferentially. Hydrolysis would occur either from myrosinase distributed within the peripheral cells layers of the root or in the rhizosphere. Based on this distribution of the GSL-myrosinase system in field grown B. napus roots, McCully et al. (2008) speculate that the major defensive role in these mature plants appears to be related to the protection of large roots during the critical seed filling stages when these roots are acting as pipelines for nutrients and water absorbed by the fine roots. The same authors suggest that the root-rot fungus $L$. maculans, which first infects the leaves and enters the root via the xylem, may be confined to the vascular bundle by this ring of cells containing high levels of 2PE-GSL (Sprague et al. 2007). The fine roots need less protection, since they are ephemeral and continuously replaced from meristems located in the outer regions of thickened roots (Table 4; M. McCully, personal communication). Such observations are consistent with the previous reports of low concentrations of GSL and ITCs (Rumberger and Marschner 2004) in the rhizosphere of intact growing Brassica plants. As the persistence of ITC released in the soil is generally short-lived (1-5 days; Brown and Morra 1997), such a system 
would ensure both protection of the main root system from major disruption as well as a continuous production and release of GSL into the rhizosphere.

\section{Evidence for GSL as mediators for belowground organisms in planta}

Despite several studies demonstrating the toxicity of various GSL hydrolysis products to a range of plant pests and pathogens in vitro (e.g. Lazzeri et al. 1993; Serra et al. 2002), there are few clear examples of resistance mechanisms in Brassicacea related to root GSL in planta. Although there are far more studies on the roles of GSL between shoots and aboveground organisms, there are some lines of evidence root GSL may similarly affect both specialist and generalist soil-dwelling pathogens, nematodes and insects. These effects are not always straightforward or direct. For example, it was speculated that GSL were involved in resistance of $B$. oleracea vegetables to the specialist clubroot pathogen Plasmodiophora brassicacae. However, it was found that higher root concentrations of indolyl (and possibly aromatic) GSL favour clubroot infection, so that resistant varieties tend to have lower root concentrations of these GSL (Ludwig-Müller et al. 1997). This is thought to be associated with the conversion of the indolyl GSL to IAA and its role in the gall formation associated with the disease.

Lab studies convincingly show that various GSL hydrolysis products are toxic to plant parasitic nematodes (Lazzeri et al. 1993; Serra et al. 2002). There is some support for these studies from field plants as well. It was demonstrated that reduced hosting of Pratylenchus neglectus in canola (B. napus) lines selected for higher concentrations of 2-PE GSL while there was no correlation with total or other GSL (Potter et al. 1998, 1999). Other nonGSL mechanisms were also involved as many plants with low numbers of $P$. neglectus, had low concentrations of 2PE-GSL $\left(<3 \mu \mathrm{mol} \mathrm{g}^{-1}\right.$ ) (Potter et al. 1999). Interestingly, a closely related nematode $P$. thornei which can occur in the same region does not host effectively on canola at all (J.A. Kirkegaard, unpublished data). Variation in the ability of different nematode species to invade and multiply within Brassica roots may be due to variations in feeding patterns of the nematodes, and hence variation in their exposure to the GSL system. This may explain why GSL (including 2PE-GSL) were found not to be involved in the reduced host status (invasion, egg laying or development) of a range of Brassicaceous crop plants to the root-knot nematode Meloidogyne javanica (McLeod et al. 2001). In contrast to the mobile migratory endoparasitic Pratylenchus spp., Meloidogyne spp. become sedentary after infection and actively suppress plant resistance responses to form a feeding structure. Consequently, there may be little release of GSL hydrolysis products. Despite the limited evidence for a direct relationship between root GSL content and nematode parasitism, specific use of suppressive impacts of Brassica in rotation remains an active research area.

Similarly, there is little evidence that GSL affect root feeding insects. Resistance or susceptibility to attack by the specialist turnip root fly (Delia floralis) was not found to be linked to total or individual GSL content, although the relatively high concentration of 2 propenyl GSL was thought to have adversely affected larval feeding and development (Birch et al. 1992). More recently, however, it was found that a related root fly species, D. radicum, produced larger pupae on Barbarea vulgaris roots with glucobarbarin (S 2-OH-2-phenylethyl GSL) as the major GSL than on B. vulgaris plants with mainly 2PE-GSL (van Leur et al. 2008).

In addition to these effects on heterotrophic organisms, GSL have also been studied for their allopathic effects on seed germination and plantplant competition. Observations that certain GSLcontaining plants can invade, colonise and dominate some natural ecosystems have led to investigations of the possible role of GSL in these allelopathic interactions. This topic is reviewed elsewhere in this issue (Müller, this issue). Interestingly, the ecological studies aiming at quantifying costs and benefits of GSL, including allelopathic properties of these compounds and their role in plant competition, generally only quantify aboveground GSL levels (e.g. Siemens et al. 2002; Lankau and Strauss 2007), thereby ignoring the role of root GSL in allelopathy.

\section{Use of GSL in agriculture: biofumigation}

In agriculture, attempts to harness the biocidal properties of GSL-containing plants have principally 
focused on the use of crop rotation, green manure crops or seed meals amended to soil (reviewed by Brown and Morra 1997; Gimsing and Kirkegaard, this issue). These studies have revealed significant potential for suppression of soil-borne pathogens and weed seed germination, although a wide variety of mechanisms unrelated to GSL are also operating, and are often inadequately separated from GSL-related suppression in field studies (Matthiessen and Kirkegaard 2006). Specific targeted investigations of the suppressive potential of root GSL were initiated in Australia during investigations of superior cereal growth following canola (B. napus) and mustard (B. juncea) in broad-acre farms (Kirkegaard et al. 1994). The dominant GSL in the roots, 2PE-GSL was shown to be highly toxic in vitro to the major soil-borne pathogens of cereals (Sarwar et al. 1998), and canola varieties with higher levels of 2-PE GSL caused a greater reduction in the level of inoculum of the take-all fungus (Gaeumannomyces graminis) in pot and field experiments (Kirkegaard et al. 2000). Subsequent studies revealed that such suppression was often not evident as disease reductions in following crops (Smith et al. 2004), partly due to the relatively low concentrations of 2PE-ITC $\left(\sim 1 \mathrm{nmol} \mathrm{g}{ }^{-1}\right.$ soil) which have been measured in the rhizosphere of growing plants (Rumberger and Marschner 2003, 2004). An example is the reported increase in levels of the biocontrol fungus Trichoderma spp. in canola rhizospheres (Kirkegaard et al. 2004), which has been shown to be highly tolerant of 2PE-ITC in vitro (Smith and Kirkegaard 2002).

A much wider scope to utilize GSL-containing plants exists in horticultural systems where a variety of species can be utilized as green manures and the whole plant can be incorporated at selected times to maximize the GSL hydrolysis products released (Matthiessen and Kirkegaard 2006). In this context, there has been a stronger emphasis on shoot GSL for several reasons. Firstly in a wide screen of 76 entries, roots contributed only $24 \%$ of total plant GSL at the flowering stage (range 2-81\%) due to their lower biomass (Kirkegaard and Sarwar 1998). In addition, the more volatile aliphatic GSL, such as 2-propenyl GSL, which dominate the shoot material in many mustard species selected for biofumigation (B. juncea, B. nigra, B. carinata), are considered to better mimic the action of synthetic ITC-based soil fumigants, such as methyl-ITC, because the higher volatility enhanced movement through the soil, and less inactivation of volatile activity (Matthiessen and Shackleton 2005). An obvious difference from an evolutionary perspective is that roots are in continual contact with the soil and likely to be releasing constant low concentrations of GSL into the soil $\left(\sim 1 \mathrm{nmol} \mathrm{g}^{-1}\right)$, whereas pest control using soil fumigants relies on single high doses (up to $1,500 \mathrm{nmol} \mathrm{g}^{-1}$ ). In this context a focus on shootbased ITC for biofumigation may be appropriate.

Similarly, GSL containing plants may be grown to reduce insect pest populations. In New Zealand, the Australian soldier fly (Inopus rubriceps) is an important pest as larval feeding on roots can devastate grass pastures. Control has relied on either cultivation measures or insecticide added to the seed. 2PE-ITC isolated from the roots of fodder kale (B. oleracae) was found to be insecticidal to soldier fly larvae (Lowe et al. 1971). Similarly, kale or fodder radish (Raphanus sativus) sown directly into infected pastures could provide control similar to that achieved with insecticides (76-86\% reduction; Blank et al. 1982). The authors suggest that GSL hydrolysis products from roots may have either insecticidal or antifeedant effects. The effectiveness of GSL containing crops as biofumigants may be increased by selecting for higher levels of the effective GSL (Kirkegaard et al. 2001). Additionally, the GSL contents and the effectiveness of weed suppression may be increased by inducing the standing crop by mechanical damage 2 weeks before it is incorporated in the soil (Kruidhof et al. 2008).

\section{Conclusions}

By reviewing the current literature on constitutive levels as well as induction of GSL in roots and shoots, we have been able to identify some general patterns that may help us to understand better the role of these compounds in natural and managed systems. Clearly, the levels, distribution and biosynthesis of GSL have been much better defined for the aboveground than for the belowground plant parts. Due to this focus on aboveground plant parts, we may be literally blind to half the story regarding the ecological and agronomical importance of GSL. We therefore argue that more effort should be going into analyzing the belowground GSL profiles and their 
role in soil ecological processes. It would provide us with a more profound insight into possible evolutionary and ecological mechanisms that have shaped the observed diversity in GSL profiles. In addition, it would greatly benefit plant breeders wishing to manipulate GSL composition of crop species in a tissue or developmentally specific manner.

Acknowledgements The authors are grateful to Jonathan Gershenzon, Ute Wittstock and Caroline Müller for the invitation to write this review. We thank F. ten Hooven for assistance with the Arabidopsis experiments and R. Gols, Wageningen University, and J.A. Harvey, NIOO-KNAW, for their permission to use unpublished data. N.M. van Dam is funded by a NWO VIDI Grant, No. 864-02-001, of the Netherlands Organisation for Scientific Research. J.A. Kirkegaard's research on root GSL in Australia was funded through several grants from the Grains Research and Development Corporation (GRDC). Publication 4290 NIOO-KNAW Netherlands Institute of Ecology.

Open Access This article is distributed under the terms of the Creative Commons Attribution Noncommercial License which permits any noncommercial use, distribution, and reproduction in any medium, provided the original author(s) and source are credited.

\section{References}

Agerbirk N, de Vos M, Kim JH et al (this issue) Indole glucosinolate breakdown and its biological effects. Phytochem Rev. doi:10.1007/s11101-008-9098-0

Agerbirk N, Olsen CE, Sorensen H (1998) Initial and final products, nitriles, and ascorbigens produced in myrosinase-catalyzed hydrolysis of indole glucosinolates. J Agric Food Chem 46:1563-1571

Aires A, Rosa E, Carvalho R (2006) Effect of nitrogen and sulfur fertilization on glucosinolates in the leaves and roots of broccoli sprouts (Brassica oleracea var. italica). J Sci Food Agric 86:1512-1516

Bartlet E, Kiddle G, Williams I et al (1999) Wound-induced increases in the glucosinolate content of oilseed rape and their effect on subsequent herbivory by a crucifer specialist. Entmol Exp Appl 91:163-167

Bellostas N, Sorensen JC, Sorensen H (2007) Profiling glucosinolates in vegetative and reproductive tissues of four Brassica species of the U-triangle for their biofumigation potential. J Sci Food Agric 87:1586-1594

Benderoth M, Textor S, Windsor AJ et al (2006) Positive selection driving diversification in plant secondary metabolism. Proc Natl Acad Sci USA 103:9118-9123

Bennett RN, Mellon FA, Foidl N et al (2003) Profiling glucosinolates and phenolics in vegetative and reproductive tissues of the multi-purpose trees Moringa oleifera L. (horseradish tree) and Moringa stenopetala L. J Agric Food Chem 51:3546-3553

Bennett RN, Mellon FA, Rosa EAS et al (2004) Profiling glucosinolates, flavonoids, alkaloids, and other secondary metabolites in tissues of Azima tetracantha L. (Salvadoraceae). J Agric Food Chem 52:5856-5862

Bialy Z, Oleszek W, Lewis J et al (1990) Allelopathic potential of glucosinolates (mustard oil glycosides) and their degradation products against wheat. Plant Soil 129:277-281

Birch ANE, Griffiths DW, Hopkins RJ et al (1992) Glucosinolate responses of swede, kale, forage and oilseed rape to root damage by turnip root fly (Delia floralis) larvae. J Sci Food Agric 60:1-9

Blank RH, Robertson LN, McMeikan WB et al (1982) Summer crops of direct-drilled kale (Brassica oleracea) and fodder radish (Raphanus sativus) to control australian soldier fly (Inopus rubriceps). New Zeal J Exp Agric 10:83-86

Bodnaryk RP (1994) Potent effect of jasmonates on indole glucosinolates in oilseed rape and mustard. Phytochemistry 35:301-305

Borek V, Elberson LR, McCaffrey JP et al (1995) Toxicity of aliphatic and aromatic isothiocyanates to eggs of the black vine weevil (Coleoptera, Curculionidae). J Econ Entomol 88:1192-1196

Borek V, Elberson LR, McCaffrey JP et al (1998) Toxicity of isothiocyanates produced by glucosinolates in brassicaceae species to black ville weevil eggs. J Agric Food Chem 46:5318-5323

Brader G, Mikkelsen MD, Halkier BA et al (2006) Altering glucosinolate profiles modulates disease resistance in plants. Plant J 46:758-767

Brown PD, Morra MJ (1997) Control of soil-borne plant pests using glucosinolate-containing plants. Adv Agronom 61:167-231

Brown PD, Tokuhisa JG, Reichelt M et al (2003) Variation of glucosinolate accumulation among different organs and developmental stages of Arabidopsis thaliana. Phytochemistry 62:471-481

Burow M, Zhang Z-Y, Ober JA et al (2008) ESP and ESM1 mediate indol-3-acetonitrile production from indol-3-ylmethyl glucosinolate in Arabidopsis. Phytochemistry 69:663-671

Castro A, Aires A, Rosa E et al (2004) Distribution of gucosinolates in Brassica oleracea cultivars. Phyton-Annales Rei Botanicae 44:133-143

Charron CS, Sams CE (2004) Glucosinolate content and myrosinase activity in rapid-cycling Brassica oleracea grown in a controlled environment. J Am Soc Hort Sci 129:321-330

Chen SX, Petersen BL, Olsen CE et al (2001) Long-distance phloem transport of glucosinolates in Arabidopsis. Plant Physiol 127:194-201

Chew FS (1988) Biological effects of glucosinolates. In: Cutler HG (ed) Biologically active natural products. ACS, Washington DC

Coleman D, Crossley D Jr, Hendrix P (2004) Fundamentals in soil ecology. Academic Press, New York

Czechowski T, Bari RP, Stitt M et al (2004) Real-time RTPCR profiling of over 1400 Arabidopsis transcription factors: unprecedented sensitivity reveals novel root- and shoot-specific genes. Plant J 38:366-379

De Smet I, Jürgens G (2007) Patterning the axis in plants-auxin in control. Curr Opin Genet Dev 17:337-343

Doughty KJ, Kiddle GA, Pye BJ et al (1995) Selective induction of glucosinolates in oilseed rape leaves by methyl jasmonate. Phytochemistry 38:347-350 
Fahey JW, Zalcmann AT, Talalay P (2001) The chemical diversity and distribution of glucosinolates and isothiocyanates among plants. Phytochemistry 56:5-51

Feeny P, Rosenberry L (1982) Seasonal-variation in the glucosinolate content of North American Brassica nigra and Dentaria species. Biochem Syst Ecol 10:23-32

Galletti S, Barillari J, Iori R et al (2006) Glucobrassicin enhancement in woad (Isatis tinctoria) leaves by chemical and physical treatments. J Sci Food Agric 86:1833-1838

Gigolashvili T, Berger B, Flügge U-I. Specific and coordinated control of indolic and aliphatic glucosinolate biosynthesis by R2R3-MYB transcription factors in Arabidopsis thaliana. Phytochem Rev (this issue)

Gigolashvili T, Berger B, Mock H-P et al (2007a) The transcription factor HIG1/MYB51 regulates indolic glucosinolate biosynthesis in Arabidopsis thaliana. Plant $\mathbf{J}$ 50:886-901

Gigolashvili T, Yatusevich R, Berger B et al (2007b) The R2R3-MYB transcription factor HAG1/MYB28 is a regulator of methionine-derived glucosinolate biosynthesis in Arabidopsis thaliana. Plant J 51:247-261

Gigolashvili T, Engqvist M, Yatusevich R et al (2008) HAG2/ MYB76 and HAG3/MYB29 exert a specific and coordinated control on the regulation of aliphatic glucosinolate biosynthesis in Arabidopsis thaliana. New Phytol 177:627-642

Gimsing AL, Kirkegaard JA. Glucosinolates and biofumigation: fate of glucosinolates and their hydrolysis products in soil. Phytochem Rev (this issue)

Grieneisen VA, Xu J, Maree AFM et al (2007) Auxin transport is sufficient to generate a maximum and gradient guiding root growth. Nature 449:1008-1013

Grubb CD, Abel S (2006) Glucosinolate metabolism and its control. TIPS 11:89-100

Harley JL, Harley EL (1987) A check-list of mycorrhiza in the british flora. New Phytol 105:1-102

Hirai MY, Sugiyama K, Sawada Y et al (2007) Omics-based identification of Arabidopsis Myb transcription factors regulating aliphatic glucosinolate biosynthesis. Proc Natl Acad Sci USA 104:6478-6483

Jones CG, Firn RD (1991) On the evolution of plant secondary chemical diversity. Phil Trans Proc Roy Soc London B 333:273-280

Jost R, Altschmied L, Bloem E et al (2005) Expression profiling of metabolic genes in response to methyl jasmonate reveals regulation of genes of primary and secondary sulfur-related pathways in Arabidopsis thaliana. Photosynth Res 86:491-508

Karban R, Agrawal AA, Thaler JS et al (1999) Induced plant responses and information content about risk of herbivory. Trends Ecol Evol 14:443-447

Kiddle GA, Doughty KJ, Wallsgrove RM (1994) Salicylic acid-induced accumulation of glucosinolates in oilseed rape (Brassica napus L.) leaves. J Exp Bot 45:1343-1346

Kim SJ, Ishii G (2006) Glucosinolate profiles in the seeds, leaves and roots of rocket salad (Eruca sativa Mill.) and antioxidative activities of intact plant powder and purified 4-methoxyglucobrassicin. Soil Sci Plant Nutr 52:394-400

Kim JH, Jander G (2007) Myzus persicae (green peach aphid) feeding on Arabidopsis induces the formation of a deterrent indole glucosinolate. Plant J 49:1008-1019
Kirkegaard JA, Sarwar M (1998) Biofumigation potential of brassicas-I. Variation in glucosinolate profiles of diverse field-grown brassicas. Plant Soil 201:71-89

Kirkegaard JA, Sarwar M (1999) Glucosinolate profiles of Australian canola (Brassica napus annua L.) and Indian mustard (Brassica juncea L.) cultivars: implications for biofumigation. Aust J Agric Res 50:315-324

Kirkegaard JA, Gardner PA, Angus JF et al (1994) Effect of Brassica break crops in the growth and yield of wheat. Aust J Agric Res 45:529-545

Kirkegaard JA, Sarwar M, Wong PTW et al (2000) Field studies on the biofumigation of take-all by Brassica break crops. Aust J Agric Res 51:445-456

Kirkegaard JA, Rebetzke GJ, Richards RA (2001) Inheritance of root glucosinolate content in canola. Aust J Agric Res 52:745-753

Kirkegaard JA, Simpfendorfer S, Holland J et al (2004) Effect of previous crops on crown rot and yield of durum and bread wheat in northern NSW. Aust J Agric Res 55:321-334

Kliebenstein DJ. A quantitative genetics and ecological model system: understanding the aliphatic glucosinolate biosynthetic network via QTLs. Phytochem Rev. doi: 10.1007/s11101-008-9102-8

Kliebenstein DJ, Figuth A, Mitchell-Olds T (2002) Genetic architecture of plastic methyl jasmonate responses in Arabidopsis thaliana. Genetics 161:1685-1696

Kruidhof H, Bastiaans L, van Dam N et al (2008) Weed suppression by cover crops; can mechanical wounding induce the production of allelochemicals? Ann Appl Biol (in review)

Laegdsmand M, Gimsing AL, Strobel BW et al (2007) Leaching of isothiocyanates through intact soil following simulated biofumigation. Plant Soil 291:81-92

Lambdon PW, Hassall M (2005) How should toxic secondary metabolites be distributed between the leaves of a fastgrowing plant to minimize the impact of herbivory? Funct Ecol 19:299-305

Lankau RA, Strauss SY (2007) Mutual feedbacks maintain both genetic and species diversity in a plant community. Science 317:1561-1563

Lazzeri L, Tacconi R, Palmieri S (1993) In vitro activity of some glucosinolates and their reaction-products toward a population of the nematode Heterodera schachtii. J Agric Food Chem 41:825-829

Li X, Kushad MM (2004) Correlation of glucosinolate content to myrosinase activity in horseradish (Armoracia rusticana). J Agric Food Chem 52:6950-6955

Liang YS, Choi YH, Kim HK et al (2006) Metabolomic analysis of methyl jasmonate treated Brassica rapa leaves by 2-dimensional NMR spectroscopy. Phytochemistry 67:2503-2511

Loivamäki M, Holopainen JK, Nerg AM (2004) Chemical changes induced by methyl jasmonate in oilseed rape grown in the laboratory and in the field. J Agric Food Chem 52:7607-7613

Lowe MD, Henzell RF, Taylor HJ (1971) Insecticidal activity to soldier fly larvae, Inopus rubriceps (Macq), of isothiocyanates occurring in choumoellier (Brassica oleracea cv.). New Zeal J Sci 14:322

Ludwig-Müller J, Schubert B, Pieper K et al (1997) Glucosinolate content in susceptible and resistant Chinese cabbage varieties during development of clubroot disease. Phytochemistry 44:407-417 
Ludwig-Müller J, Bennett RN, Kiddle G et al (1999) The host range of Plasmodiophora brassicae and its relationship to endogenous glucosinolate content. New Phytol 141:443-458

Matthiessen JN, Kirkegaard JA (2006) Biofumigation and enhanced biodegradation: opportunity and challenge in soilborne pest and disease management. Crit Rev Plant Sci 25:235-265

Matthiessen JN, Shackleton MA (2005) Biofumigation: environmental impacts on the biological activity of diverse pure and plant-derived isothiocyanates. Pest Manag Sci 61:1043-1051

McCully M, Miller C, Sprague S et al (2008) The distribution of glucosinolates and sulphur-rich cells in roots of fieldgrown canola (Brassica napus). New Phytol (in review)

McLeod RW, Kirkegaard JA, Steel CC (2001) Invasion, development, growth and egg laying by Meloidogyne javanica in Brassicaceae crops. Nematology 3:463-472

Mewis I, Tokuhisa JG, Schultz JC et al (2006) Gene expression and glucosinolate accumulation in Arabidopsis thaliana in response to generalist and specialist herbivores of different feeding guilds and the role of defense signaling pathways. Phytochemistry 67:2450

Mikkelsen MD, Petersen BL, Glawischnig E et al (2003) Modulation of CYP79 genes and glucosinolate profiles in Arabidopsis by defense signaling pathways. Plant Physiol 131:298-308

Mithen RF (2001) Glucosinolates and their degradation products. Adv Bot Res 35:213-262

Mithen RF, Lewis BG (1986) In vitro activity of glucosinolates and their products against Leptosphaeria maculans. Trans Br Mycol Soc 87:433-440

Müller C. Role of glucosinolates in plant invasiveness. Phytochem Rev (this issue)

Petersen BL, Chen SX, Hansen CH et al (2002) Composition and content of glucosinolates in developing Arabidopsis thaliana. Planta 214:562-571

Potter MJ, Davies K, Rathjen AJ (1998) Suppressive impact of glucosinolates in Brassica vegetative tissues on root lesion nematode Pratylenchus neglectus. J Chem Ecol 24:67-80

Potter MJ, Vanstone VA, Davies KA et al (1999) Reduced susceptibility of Brassica napus to Pratylenchus neglectus in plants with elevated root levels of 2-phenylethyl glucosinolate. J Nematol 31:291-298

Potter MJ, Vanstone VA, Davies KA et al (2000) Breeding to increase the concentration of 2-phenylethyl glucosinolate in the roots of Brassica napus. J Chem Ecol 26: $1811-1820$

Rodman JE, Louda SM (1984) Phenology of glucosinolate concentrations in roots, stems and leaves of Cardamine cordifolia. Biochem Syst Ecol 12:37-46

Rosa EAS (1997) Daily variation in glucosinolate concentrations in the leaves and roots of cabbage seedlings in two constant temperature regimes. J Sci Food Agric 73: 364-368

Rosa EAS, Rodrigues PMF (1998) The effect of light and temperature on glucosinolate concentration in the leaves and roots of cabbage seedlings. J Sci Food Agric 78: 208-212

Rumberger A, Marschner P (2003) 2-Phenylethylisothiocyanate concentration and microbial community composition in the rhizosphere of canola. Soil Biol Biochem 35: 445-452

Rumberger A, Marschner P (2004) 2-Phenylethylisothiocyanate concentration and bacterial community composition in the rhizosphere of field-grown canola. Funct Plant Biol 31:623-631

Sarwar M, Kirkegaard JA, Wong PTW et al (1998) Biofumigation potential of brassicas-III. In vitro toxicity of isothiocyanates to soil-borne fungal pathogens. Plant Soil 201:103-112

Serra B, Rosa E, Iori R et al (2002) In vitro activity of 2-phenylethyl glucosinolate, and its hydrolysis derivatives on the root-knot nematode Globodera rostochiensis (Woll.). Scientia Horticulturae 92:75-81

Siemens DH, Garner SH, Mitchell-Olds T et al (2002) Cost of defense in the context of plant competition: Brassica rapa may grow and defend. Ecology 83:505-517

Skirycz A, Reichelt M, Burow M et al (2006) DOF transcription factor AtDof1.1 (OBP2) is part of a regulatory network controlling glucosinolate biosynthesis in Arabidopsis. Plant J 47:10-24

Smetanska I, Krumbein A, Schreiner M et al (2007) Influence of salicylic acid and methyl jasmonate on glucosinolate levels in turnip. J Hortic Sci Biotechnol 82:690-694

Smith BJ, Kirkegaard JA (2002) In vitro inhibition of soil microorganisms by 2-phenylethyl isothiocyanate. Plant Pathol 51:585-593

Smith BJ, Kirkegaard JA, Howe GN (2004) Impacts of Brassica break-crops on soil biology and yield of following wheat crops. Aust J Agric Res 55:1-11

Soler R, Bezemer TM, Van der Putten WH et al (2005) Root herbivore effects on above-ground herbivore, parasitoid and hyperparasitoid performance via changes in plant quality. J Anim Ecol 74:1121-1130

Soler R, Bezemer TM, Cortesero AM et al (2007) Impact of foliar herbivory on the development of a root-feeding insect and its parasitoid. Oecologia 152:257-264

Sprague SJ, Watt M, Kirkegaard JA et al (2007) Pathways of infection of Brassica napus roots by Leptosphaeria maculans. New Phytol 176:211-222

Staswick PE, Tiryaki I (2004) The oxylipin signal jasmonic acid is activated by an enzyme that conjugates it to isoleucine in Arabidopsis. Plant Cell 16:2117-2127

Tolrà RP, Poschenrieder C, Alonso R et al (2001) Influence of zinc hyperaccumulation on glucosinolates in Thlaspi caerulescens. New Phytol 151:621-626

Tolrà R, Pongrac P, Poschenrieder C et al (2006) Distinctive effects of cadmium on glucosinolate profiles in Cd hyperaccumulator Thlaspi praecox and non-hyperaccumulator Thlaspi arvense. Plant Soil 288:333-341

van Dam NM, Raaijmakers CE (2006) Local and systemic induced responses to cabbage root fly larvae (Delia radicum) in Brassica nigra and B. oleracea. Chemoecology 16:17-24

van Dam NM, Harvey JA, Wäckers FL et al (2003) Interactions between aboveground and belowground induced responses against phytophages. Basic Appl Ecol 4:63-77

van Dam NM, Witjes L, Švatoš A (2004) Interactions between aboveground and belowground induction of glucosinolates in two wild Brassica species. New Phytol 161: $801-810$ 
van der Putten WH, Vet LEM, Harvey JA et al (2001) Linking above- and belowground interactions of plants, herbivores and their antagonists. Trends Ecol Evol 16:547-554

van Leur H (2008) Genetics, chemistry and ecology of a qualitative glucosinolate polymorphism in Barbarea vulgaris. Ph.D. Thesis, Wageningen University, Wageningen, The Netherlands

van Leur H, Raaijmakers CE, van Dam NM (2006) A heritable glucosinolate polymorphism within natural populations of Barbarea vulgaris. Phytochemistry 67:1214-1223

van Leur H, Raaijmakers CE, Van Dam NM (2008) Reciprocal interactions between the cabbage root fly (Delia radicum) and two glucosinolate phenotypes of Barbarea vulgaris. Entmol Exp Appl (in press)
Vaughn SF, Berhow MA (1999) Allelochemicals isolated from tissues of the invasive weed garlic mustard (Alliaria petiolata). J Chem Ecol 25:2495-2504

Vierheilig H, Bennett R, Kiddle G et al (2000) Differences in glucosinolate patterns and arbuscular mycorrhizal status of glucosinolate-containing plant species. New Phytol 146:343-352

Wittstock U, Gershenzon J (2002) Constitutive plant toxins and their role in defense against herbivores and pathogens. Curr Opin Plant Biol 5:300-307

Yan XF, Chen SX (2007) Regulation of plant glucosinolate metabolism. Planta 226:1343-1352 